\title{
Application of Quantum Chemistry Insights to the Prediction of Phase Equilibria in Associating
}

\section{Systems}

John Towne, Xiaodong Liang*, Georgios M. Kontogeorgis

Center for Energy Resources Engineering

Department of Chemical and Biochemical Engineering

Technical University of Denmark

Søltofts Plads, Building 229

2800 Kgs. Lyngby, Denmark

Corresponding author:

*E-mail: xlia@kt.dtu.dk. Tel.: 0045-45252877. 


\section{S1. Parameterization}

Table S1 lists the compounds studied in this work. Parameter sets for all compounds in this work are detailed in this section. Representative parameters for PC-SAFT and CPA were taken from a variety of literature sources (see Tables S2 and S3). Information for the parameter sets shown in Tables S2 and S3 (such as experimental data sources, temperature ranges, objective function used for fitting, and correlation performance) can be found in the original literature sources. Where there were multiple parameters found for a given compound, judgement was applied to select a reasonable 'best' set (typically selecting the most recently regressed parameters or using parameters from studies where the topic was parameterizing a specific compound).

Table S1. List of compounds and the reduced temperature range used to generate the parameter sets in Tables S4-S7.

\begin{tabular}{cc}
\hline Compound & Temperature Range, $\mathrm{T}_{\mathrm{r}}$ \\
\hline Carbon Dioxide $^{\mathrm{a}}$ & $0.712-0.9$ \\
Hydrogen Sulfide $^{\mathrm{a}}$ & $0.503-0.9$ \\
Methanethiol $^{\text {Ammonia }}{ }^{\mathrm{a}}$ & $0.4-0.9$ \\
Methylamine $^{\text {a }}$ & $0.482-0.9$ \\
Water $^{\text {a }}$ & $0.417-0.9$ \\
Methanol $^{\text {Ethanol }}$ & $0.422-0.9$ \\
Propanol $_{\text {Ethylene Glycol }}$ & $0.4-0.9$ \\
Hydrogen Fluoride $^{\mathrm{a}}$ & $0.4-0.9$ \\
Hydrogen Chloride $^{\mathrm{a}}$ & $0.4-0.9$ \\
\hline
\end{tabular}

(a) Lower bound defined by $T_{r}=T_{\text {triple point }} / T_{c}$. 
Table S2. PC-SAFT literature parameter sets.

\begin{tabular}{ccccccc}
\hline Compound & Scheme & $\mathrm{m}$ & $\begin{array}{c}\sigma \\
(\AA)\end{array}$ & $\begin{array}{c}\varepsilon / \mathrm{k} \\
(\mathrm{K})\end{array}$ & $\kappa_{\mathrm{AB}}$ & $\begin{array}{c}\varepsilon_{\mathrm{AB}} / \mathrm{R} \\
(\mathrm{K})\end{array}$ \\
\hline Methylamine $^{1}$ & $2 \mathrm{~B}^{\mathrm{b}}$ & 2.397 & 2.891 & 214.9 & 0.0951 & 684 \\
$\begin{array}{c}\text { Water } \\
{ }^{2}\end{array}$ & $4 \mathrm{C}^{\mathrm{a}}$ & 2.000 & 2.345 & 171.7 & 0.3048 & 1704 \\
Methanol $^{3}$ & $2 \mathrm{~B}^{\mathrm{a}}$ & 2.877 & 2.576 & 164.9 & 0.3608 & 2304 \\
Ethanol $^{4}$ & $2 \mathrm{~B}^{\mathrm{a}}$ & 2.635 & 3.058 & 191.9 & 0.0789 & 2574 \\
Propanol $^{4}$ & $2 \mathrm{~B}^{\mathrm{a}}$ & 2.719 & 3.351 & 231.5 & 0.03183 & 2464 \\
Ethylene Glycol $^{5}$ & $4 \mathrm{C}^{\mathrm{a}}$ & 2.354 & 3.319 & 280.3 & 0.0867 & 2007 \\
Carbon Dioxide $^{6}$ & $4 \mathrm{C}^{\mathrm{b}}$ & 2.228 & 2.731 & 157.3 & 0.0287 & 307 \\
\hline
\end{tabular}

(a) the simplified PC-SAFT, (b) PC-SAFT. The simplified PC-SAFT and PC-SAFT have in principle the same pure component parameters, while for some historic reasons some published pure component parameters might have a conversion factor of $\pi / 6$, as mentioned in some publications.

Table S3. CPA literature parameter sets.

\begin{tabular}{|c|c|c|c|c|c|c|}
\hline Compound & Scheme & $\begin{array}{c}\mathrm{b} \\
\left(\mathrm{cm}^{3} / \mathrm{mol}\right)\end{array}$ & $\begin{array}{c}\mathrm{a} / \mathrm{Rb} \\
(\mathrm{K})\end{array}$ & $\mathrm{c} 1$ & $\beta_{\mathrm{AB}} \times 10^{3}$ & $\begin{array}{c}\varepsilon_{\mathrm{AB}} / \mathrm{R} \\
(\mathrm{K})\end{array}$ \\
\hline Carbon Dioxide ${ }^{7}$ & $4 \mathrm{C}$ & 28.4 & 1330 & 0.69 & 29.7 & 472 \\
\hline Hydrogen Sulfide ${ }^{8}$ & $4 \mathrm{C}$ & 29.5 & 1618 & 0.54 & 47.5 & 448 \\
\hline Methylamine ${ }^{9}$ & $2 \mathrm{~B}$ & 36.1 & 1829 & 0.60 & 33.7 & 1379 \\
\hline Water $^{3}$ & $4 \mathrm{C}$ & 14.8 & 994 & 1.47 & 141.9 & 1574 \\
\hline Methanol $^{3}$ & $2 \mathrm{~B}$ & 32.1 & 1540 & 0.92 & 57.8 & 2315 \\
\hline Ethanol $^{7}$ & $2 \mathrm{~B}$ & 49.1 & 2124 & 0.74 & 8.0 & 2590 \\
\hline Propanol $^{7}$ & $2 \mathrm{~B}$ & 64.1 & 2235 & 0.92 & 8.1 & 2526 \\
\hline Ethylene Glycol $^{7}$ & $4 \mathrm{C}$ & 51.4 & 2532 & 0.67 & 14.1 & 2376 \\
\hline
\end{tabular}


DIPPR $^{10}$ correlations were used to generate pseudo-experimental saturated liquid density and vapor pressure data in this study. The reduced temperature range used for parameterizing each compound are presented in Table S1. The objective function for minimization is shown in Eq. (8) of the main paper. Particle Swarm Optimization was used to search for an initial minimum followed by local refinement with Nelder-Mead Simplex. In many cases, additional manual searches were conducted to identify improved minima. Average absolute deviations (\%AAD) as a measure of vapor pressure and liquid density correlation performance for the parameter sets in Tables S4-S7 are presented in Tables S8-S9. Tables S10-S11 contain additional parameter sets for methylamine based on different sources of literature data.

Table S4. PC-SAFT 5-parameter regression $\left(\varepsilon_{A_{i} B_{j}} / R \geq T_{0} \ln (2) \cong 207 \mathrm{~K}\right.$ constraint applied).

\begin{tabular}{ccccccc}
\hline Compound & Scheme & $\mathrm{m}$ & $\begin{array}{c}\sigma \\
(\AA)\end{array}$ & $\begin{array}{c}\varepsilon / \mathrm{k} \\
(\mathrm{K})\end{array}$ & $\kappa_{\mathrm{AB}}$ & $\begin{array}{c}\varepsilon_{\mathrm{AB}} / \mathrm{R} \\
(\mathrm{K})\end{array}$ \\
\hline Carbon Dioxide & 4C & 2.921 & 2.449 & 81.1 & 0.5256 & 522 \\
Hydrogen Sulfide & 4C & 3.245 & 2.410 & 108.1 & 2.1086 & 241 \\
Methanethiol & 2B & 1.640 & 3.518 & 294.0 & 0.0086 & 687 \\
Ammonia & 4B & 3.825 & 1.986 & 121.2 & 1.0190 & 658 \\
Methylamine & 2B & 3.135 & 2.604 & 197.9 & 0.0000 & 1263 \\
Water & 4C & 2.876 & 2.047 & 180.9 & 0.3781 & 1327 \\
Methanol & 2B & 2.969 & 2.585 & 179.6 & 0.1846 & 2065 \\
Ethanol & 2B & 2.800 & 3.003 & 195.1 & 0.0483 & 2415 \\
Propanol & 2B & 3.161 & 3.170 & 219.6 & 0.0279 & 2249 \\
Ethylene Glycol & 4C & 3.498 & 2.844 & 234.8 & 0.1289 & 1746 \\
Hydrogen Fluoride & 2B & 2.126 & 2.164 & 118.0 & 4.2535 & 1677 \\
Hydrogen Chloride & 2B & 2.754 & 2.393 & 111.3 & 3.0229 & 457 \\
\hline
\end{tabular}


Table S5. PC-SAFT 4-parameter regression with $\varepsilon_{A_{i} B_{j}} / R$ estimated from $\left|\Delta H_{S A P T} / R\right|$.

\begin{tabular}{ccccccc}
\hline Compound & Scheme & $\mathrm{m}$ & $\begin{array}{c}\sigma \\
(\AA)\end{array}$ & $\begin{array}{c}\varepsilon / \mathrm{k} \\
(\mathrm{K})\end{array}$ & $\kappa_{\mathrm{AB}}$ & $\begin{array}{c}\varepsilon_{\mathrm{AB}} / \mathrm{R} \\
(\mathrm{K})\end{array}$ \\
\hline Carbon Dioxide & 4C & 2.873 & 2.463 & 80.6 & 0.5017 & 534 \\
Hydrogen Sulfide & 4C & 3.252 & 2.408 & 107.8 & 2.1107 & 242 \\
Methanethiol & 2B & 1.659 & 3.502 & 292.8 & 0.0064 & 715 \\
Ammonia & 4B & 3.607 & 2.023 & 120.5 & 0.7007 & 791 \\
Methylamine & 2B & 3.135 & 2.604 & 197.9 & 0.0000 & 1280 \\
Water & 4C & 2.343 & 2.195 & 162.8 & 0.2253 & 1649 \\
Methanol & 2B & 2.990 & 2.578 & 179.4 & 0.1900 & 2052 \\
Ethanol & 2B & 2.921 & 2.957 & 192.4 & 0.0568 & 2358 \\
Propanol & 2B & 2.981 & 3.240 & 226.0 & 0.0215 & 2318 \\
Ethylene Glycol & 4C & 3.000 & 2.968 & 186.4 & 0.0848 & 2416 \\
Hydrogen Fluoride & 2B & 1.821 & 2.278 & 117.8 & 3.0749 & 1791 \\
Hydrogen Chloride & 2B & 2.520 & 2.466 & 112.0 & 1.9596 & 572 \\
\hline
\end{tabular}

Table S6. CPA 5-parameter regression $\left(\varepsilon_{A_{i} B_{j}} / R \geq T_{0} \ln (2) \cong 207 \mathrm{~K}\right.$ constraint applied).

\begin{tabular}{ccccccc}
\hline Compound & Scheme & $\begin{array}{c}\mathrm{b} \\
\left(\mathrm{cm}^{3} / \mathrm{mol}\right)\end{array}$ & $\begin{array}{c}\mathrm{a} / \mathrm{Rb} \\
(\mathrm{K})\end{array}$ & $\mathrm{c} 1$ & $\beta_{\mathrm{AB}} \times 10^{3}$ & $\begin{array}{c}\varepsilon_{\mathrm{AB}} / \mathrm{R} \\
(\mathrm{K})\end{array}$ \\
\hline Carbon Dioxide & $4 \mathrm{C}$ & 28.4 & 1331 & 0.69 & 29.1 & 477 \\
Hydrogen Sulfide & $4 \mathrm{C}$ & 29.5 & 1626 & 0.54 & 46.2 & 446 \\
Methanethiol & 2B & 43.7 & 2317 & 0.53 & 31.0 & 881 \\
Ammonia & $4 \mathrm{~B}$ & 19.8 & 1043 & 1.39 & 326.2 & 668 \\
Methylamine & 2B & 36.1 & 2172 & 0.84 & 14.1 & 657 \\
Water & 4C & 14.9 & 1141 & 0.96 & 90.3 & 1774 \\
Methanol & 2B & 32.8 & 1642 & 1.03 & 75.0 & 2071 \\
Ethanol & 2B & 47.9 & 1828 & 0.90 & 16.9 & 2531 \\
Propanol & 2B & 64.3 & 2242 & 1.00 & 11.5 & 2318 \\
Ethylene Glycol & 4C & 50.9 & 2531 & 0.63 & 13.7 & 2416 \\
Hydrogen Fluoride & 2B & 13.9 & 815 & 1.19 & 3946.5 & 1388 \\
Hydrogen Chloride & 2B & 24.2 & 1058 & 0.81 & 649.9 & 550 \\
\hline
\end{tabular}


Table S7. CPA 4-parameter regression with $\varepsilon_{A_{i} B_{j}} / R$ estimated from $\left|\Delta H_{S A P T} / R\right|$.

\begin{tabular}{ccccccc}
\hline Compound & Scheme & $\begin{array}{c}\mathrm{b} \\
\left(\mathrm{cm}^{3} / \mathrm{mol}\right)\end{array}$ & $\begin{array}{c}\mathrm{a} / \mathrm{Rb} \\
(\mathrm{K})\end{array}$ & $\mathrm{c} 1$ & $\beta_{\mathrm{AB}} \times 10^{3}$ & $\begin{array}{c}\varepsilon_{\mathrm{AB}} / \mathrm{R} \\
(\mathrm{K})\end{array}$ \\
\hline Carbon Dioxide & $4 \mathrm{C}$ & 28.4 & 1334 & 0.66 & 23.0 & 534 \\
Hydrogen Sulfide & $4 \mathrm{C}$ & 29.4 & 1645 & 0.62 & 100.9 & 242 \\
Methanethiol & 2B & 43.6 & 2350 & 0.58 & 29.1 & 715 \\
Ammonia & $4 \mathrm{~B}$ & 19.7 & 1032 & 1.32 & 231.0 & 791 \\
Methylamine & 2B & 36.0 & 1827 & 0.66 & 41.9 & 1280 \\
Water & 4C & 15.0 & 1157 & 1.13 & 109.4 & 1649 \\
Methanol & 2B & 32.8 & 1633 & 1.05 & 79.3 & 2052 \\
Ethanol & 2B & 47.9 & 1767 & 1.03 & 27.0 & 2358 \\
Propanol & 2B & 64.3 & 2242 & 1.00 & 11.5 & 2318 \\
Ethylene Glycol & 4C & 50.9 & 2531 & 0.63 & 13.7 & 2416 \\
Hydrogen Fluoride & 2B & 13.2 & 815 & 0.69 & 1733.0 & 1791 \\
Hydrogen Chloride & 2B & 24.1 & 1054 & 0.79 & 607.0 & 572 \\
\hline
\end{tabular}

Table S8. Performance of PC-SAFT parameter sets for saturation property correlation.

\begin{tabular}{ccccccc}
\hline \multirow{2}{*}{ Compound } & \multirow{2}{*}{$\begin{array}{c}\text { Temperature } \\
\text { Range, } \mathrm{T}_{\mathrm{r}}\end{array}$} & Scheme & \multicolumn{2}{c}{ \%AAD from 5- } & \multicolumn{2}{c}{ \%AAD farameter } \\
\cline { 4 - 7 } & & & $\rho_{\text {liq }}$ & $\mathrm{P}_{\text {sat }}$ & $\rho_{\text {liq }}$ & $\mathrm{P}_{\text {sat }}$ \\
\hline Carbon Dioxide & $0.712-0.9$ & 4C & 0.06 & 0.16 & 0.06 & 0.16 \\
Hydrogen Sulfide & $0.503-0.9$ & 4C & 0.20 & 1.08 & 0.20 & 1.08 \\
Methanethiol & $0.4-0.9$ & 2B & 0.47 & 0.46 & 0.46 & 0.48 \\
Ammonia & $0.482-0.9$ & 4B & 0.08 & 0.21 & 0.10 & 0.52 \\
Methylamine & $0.417-0.9$ & 2B & 0.41 & 0.63 & 0.41 & 0.63 \\
Water & $0.422-0.9$ & 4C & 1.14 & 0.32 & 0.94 & 1.48 \\
Methanol & $0.4-0.9$ & 2B & 0.12 & 0.79 & 0.13 & 0.78 \\
Ethanol & $0.4-0.9$ & 2B & 0.11 & 0.24 & 0.16 & 0.38 \\
Propanol & $0.4-0.9$ & 2B & 0.18 & 0.29 & 0.36 & 0.26 \\
Ethylene Glycol & $0.4-0.709$ & 4C & 0.07 & 0.17 & 0.11 & 2.54 \\
Hydrogen Fluoride & $0.412-0.9$ & 2B & 0.28 & 1.97 & 0.24 & 2.14 \\
Hydrogen Chloride & $0.490-0.878$ & 2B & 0.24 & 0.42 & 0.27 & 0.51 \\
& Average & & 0.28 & 0.56 & 0.29 & 0.91 \\
\hline
\end{tabular}


Table S9. Performance of CPA parameter sets for saturation property correlation.

\begin{tabular}{ccccccc}
\hline \multirow{2}{*}{ Compound } & \multirow{2}{*}{$\begin{array}{c}\text { Temperature } \\
\text { Range, } \mathrm{T}_{\mathrm{r}}\end{array}$} & Scheme & & \multicolumn{2}{c}{$\begin{array}{c}\text { \%AAD from 5- } \\
\text { Parameter }\end{array}$} & \multicolumn{2}{c}{$\begin{array}{c}\text { \%AD from 4-Parameter, } \\
\varepsilon_{\mathrm{AB}} / \text { R from Eq. 13 }\end{array}$} \\
\cline { 5 - 8 } & & & $\rho_{\text {liq }}$ & $\mathrm{P}_{\text {sat }}$ & $\rho_{\text {liq }}$ & $\mathrm{P}_{\text {sat }}$ \\
\hline Carbon Dioxide & $0.712-0.9$ & 4C & 0.12 & 0.02 & 0.12 & 0.07 \\
Hydrogen Sulfide & $0.503-0.9$ & 4C & 0.46 & 0.09 & 0.51 & 0.56 \\
Methanethiol & $0.4-0.9$ & 2B & 0.56 & 0.37 & 0.65 & 0.77 \\
Ammonia & $0.482-0.9$ & 4B & 0.40 & 0.05 & 0.38 & 0.33 \\
Methylamine & $0.417-0.9$ & 2B & 0.63 & 0.43 & 1.31 & 0.26 \\
Water & $0.422-0.9$ & 4C & 0.97 & 0.34 & 0.97 & 0.41 \\
Methanol & $0.4-0.9$ & 2B & 0.43 & 0.87 & 0.45 & 0.85 \\
Ethanol & $0.4-0.9$ & 2B & 0.49 & 0.57 & 0.68 & 0.68 \\
Propanol & $0.4-0.9$ & 2B & 0.81 & 0.27 & 0.81 & 0.27 \\
Ethylene Glycol & $0.4-0.709$ & 4C & 1.21 & 0.49 & 1.21 & 0.49 \\
Hydrogen Fluoride & $0.412-0.9$ & 2B & 0.34 & 1.32 & 0.22 & 2.15 \\
Hydrogen Chloride & $0.490-0.878$ & 2B & 0.39 & 0.51 & 0.38 & 0.52 \\
\multicolumn{2}{c}{ Average } & & 0.57 & 0.44 & 0.64 & 0.61 \\
\hline
\end{tabular}

Table S10. PC-SAFT 5-parameter regression for Methylamine (2B) from several data sources.

\begin{tabular}{cccccccc}
\hline Source & $\mathrm{m}$ & $\begin{array}{c}\sigma \\
(\AA)\end{array}$ & $\begin{array}{c}\varepsilon / \mathrm{k} \\
(\mathrm{K})\end{array}$ & $\kappa_{\mathrm{AB}}$ & $\begin{array}{c}\varepsilon_{\mathrm{AB}} / \mathrm{R} \\
(\mathrm{K})\end{array}$ & $\begin{array}{c}\text { \%AAD } \\
\rho_{\text {liq }}\end{array}$ & $\begin{array}{c}\text { \%AAD } \\
\mathrm{P}_{\text {sat }}\end{array}$ \\
\hline DIPPR Data & 3.135 & 2.604 & 197.9 & $4.9 \mathrm{E}-13$ & 1263 & 0.41 & 0.63 \\
NIST Web Thermo Data & 2.964 & 2.652 & 204.4 & $4.6 \mathrm{E}-12$ & 999 & 0.59 & 0.57 \\
TRC Data & 3.049 & 2.625 & 201.2 & $6.9 \mathrm{E}-05$ & 1066 & 0.50 & 0.58 \\
All DIPPR/NIST/TRC Data & 3.059 & 2.623 & 200.8 & $2.0 \mathrm{E}-11$ & 997 & 0.52 & 1.20 \\
\hline
\end{tabular}

Table S11. CPA 5-parameter regression for Methylamine (2B) from several data sources.

\begin{tabular}{cccccccc}
\hline Source & $\begin{array}{c}\mathrm{b} \\
\left(\mathrm{cm}^{3} / \mathrm{mol}\right)\end{array}$ & $\begin{array}{c}\mathrm{a} / \mathrm{Rb} \\
(\mathrm{K})\end{array}$ & $\mathrm{c} 1$ & $\beta_{\mathrm{AB}} \times 10^{3}$ & $\begin{array}{c}\varepsilon_{\mathrm{AB}} / \mathrm{R} \\
(\mathrm{K})\end{array}$ & $\begin{array}{c}\% A A D \\
\rho_{\text {liq }}\end{array}$ & $\begin{array}{c}\text { \%AAD } \\
\mathrm{P}_{\text {sat }}\end{array}$ \\
\hline DIPPR Data & 36.1 & 2172 & 0.839 & 14.1 & 657 & 0.6 & 0.4 \\
NIST Web Thermo Data & 35.7 & 1859 & 0.632 & 44.4 & 1252 & 1.1 & 0.1 \\
TRC Data & 36.0 & 1947 & 0.690 & 42.2 & 1107 & 1.0 & 0.1 \\
All DIPPR/NIST/TRC Data & 36.1 & 1944 & 0.734 & 53.8 & 1004 & 1.2 & 1.0 \\
\hline
\end{tabular}




\section{S2. Quantum Chemistry}

Application of quantum chemistry to the analysis of noncovalent interactions has accelerated in the last ten years for several reasons.

- Comprehensive review articles are available which summarize the state of the art for common calculation methods. This creates a pathway for practitioners to quickly acquire the knowledge needed to select high performing models for a particular application. ${ }^{11-13}$

- Popular calculation methods and basis sets are available in established, widely available software packages (Gaussian ${ }^{14}$, GAMESS $^{15}$, Q-Chem ${ }^{16}, \mathrm{Psi}^{17}{ }^{17}$, and many others).

- The performance of popular calculation methods (MP2, DFT, SAPT) are well studied against large databases of high accuracy benchmark values (calculations at $\operatorname{CCSD}(\mathrm{T}) / \mathrm{CBS}$ level of theory).

- General dataset of organic noncovalent complexes ${ }^{18}$

- Saturated and unsaturated hydrocarbon dimers ${ }^{19}$

- Small noncovalent complexes ${ }^{20}$

- Halogen containing noncovalent complexes ${ }^{21}$

- Sulfur containing noncovalent complexes ${ }^{22}$

○ Ion containing noncovalent complexes ${ }^{23}$

- The increasing popularity and availability of open source computational chemistry software has lowered the barrier to entry for new users. Additional benefits of open source computational chemistry projects include complete transparency as well as support from a broad developer community that maintains, extends, and documents the code base. 


\section{S2.1 Basis Sets}

The goal of a basis set is to provide an accurate representation of molecular orbitals (and calculated molecular properties) at a reasonably acceptable computational cost. Gaussian-type orbital basis sets are typically preferred due to improved computational efficiency. Jensen's review article is good discussion of how basis sets are constructed and some differences between common basis set families. ${ }^{24}$ The finite number of basis functions used for practical calculations only approximate the complete electronic wavefunction which results in basis set incompleteness error (BSIE). It is generally good to use a large basis set to minimize BSIE, though the best basis set size is sometimes dependent on the quantum chemical calculation method. Basis sets used to study noncovalent complexes should also include polarization and diffuse functions. The Dunning correlation consistent series (aug-cc-pVXZ, X=D, T, Q, ..) is commonly recommended for use with wavefunction (such as MP2 and SAPT) ${ }^{12,13}$ and electron density (such as $\omega \mathrm{B} 97 \mathrm{M}-\mathrm{V})^{11}$ calculation methods. The Ahlrichs property-optimized series (def2$\mathrm{XVPPD}, \mathrm{X}=\mathrm{TZ}, \mathrm{QZ}$ ) is another popular choice which is often recommended for use with electron density calculation methods. ${ }^{11}$

\section{S2.2 MP2}

Second Order Møller-Plesset Perturbation Theory (MP2) is an electronic wavefuction method that has been popular for several decades. It gives good results for noncovalent interactions at an acceptable computational cost (CPU time scales with system size according to $\sim \mathrm{O}\left(\mathrm{N}^{4-5}\right)$ where $\mathrm{N}$ is the number of basis functions). MP2 improves on the Hartree-Fock approximation by accounting for electron correlation, however this treatment is approximate and it tends to overbind complexes due to overestimation of dispersion. The success of MP2 in practice depends on 
the selection of a moderate size basis set so that errors from overestimation of dispersion effects are somewhat cancelled by errors caused by basis set incompleteness. The aug-cc-pVTZ basis set is recommended for hydrogen bonded or mixed influenced systems. ${ }^{12}$

\section{S2.3 DFT}

Density Functional Theory (DFT) is a class of electron density based methods that gives good results for noncovalent interactions at a lower computational cost than MP2 (CPU time scales with system size according to $\mathrm{O}\left(\mathrm{N}^{3-4}\right)$ where $\mathrm{N}$ is the number of basis functions). This significant improvement in computational performance makes DFT the most popular approach in computational chemistry. DFT functionals mainly differ in the sophistication with which the exchange-correlation functional is determined which creates a tradeoff between computational cost and performance. The inclusion of dispersion corrections is required for accurate treatment of noncovalent interactions as density functionals do not account for long-range electron correlation correctly. DFT functionals are semi-empirical meaning they have adjustable parameters (between 5 and 75 parameters depending on the functional) which are regressed against a data set of high accuracy reference properties. ${ }^{11}$ The landscape of DFT functionals is always changing as 'new and improved' models are parameterized against ever growing databases of reference properties. A recent and remarkable functional which strikes a blend between reasonable computational cost, high accuracy, and a very modest 12 adjustable parameters is $\omega B 97 \mathrm{M}-\mathrm{V}$. The Def2-QZVPPD basis set is recommended for use with $\omega \mathrm{B} 97 \mathrm{M}$ $\mathrm{V}^{25}$ 


\section{S2.4 Noncovalent Complexes and Counterpoise Correction}

It is straight forward to use MP2 and DFT methods to determine properties for an isolated molecule. When determining properties of noncovalent complexes, the overlap of wavefunctions in the region between the two molecules requires use of a different approach. There are two general strategies: the supermolecular approach and the perturbative approach which are illustrated in Figure S1.

(a)

$$
\begin{aligned}
H_{A B} \psi & =E_{A B} \psi \\
H_{A} \psi & =E_{A} \psi \\
H_{B} \psi & =E_{B} \psi
\end{aligned} \quad \rightarrow \Delta E_{\text {int }}^{A B}=E_{A B}-E_{A}-E_{B}
$$

(b)

$$
\begin{gathered}
\left(H_{A}+H_{B}+\lambda V_{A B}\right) \psi=E \psi \\
\downarrow \\
\Delta E_{\text {int }}^{A B}=E_{\text {elst }}+E_{\text {exch }}+E_{\text {ind }}+E_{\text {disp }}
\end{gathered}
$$

Figure S1. Qualitative comparison of the (a) supermolecular and (b) perturbative approaches.

In the supermolecular approach, interaction energy is calculated as the difference between the energy of a complex minus the sum of the energies of the isolated monomers. Basis set superposition error (BSSE) is a problem with the supermolecular approach which occurs in noncovalent complexes due to the overlap of wavefunctions in the region between each molecule. Overlapping wavefunctions artificially stabilize the complex by lowering the dimer energy which results in an overestimation of the complex binding energy. BSSE can be compensated for using the counterpoise correction method (illustrated in Figure S2) which includes basis sets for all molecules the calculation of both monomer and complex energies. ${ }^{26}$ 
(a)

$$
\Delta E_{i n t}=E_{A B}^{w f n=A B}-E_{A}^{w f n=A}-E_{B}^{w f n=B}
$$

(b)

$$
\Delta E_{i n t}=E_{A B}^{w f n=A B}-E_{A}^{w f n=A B}-E_{B}^{w f n=A B}
$$

Figure S2. Calculations (a) without and (b) with counterpoise correction.

The counterpoise correction method is recommended for use with MP2 when calculating binding energies for noncovalent complexes. It is more computationally expensive due to the larger basis sets required for evaluation of monomer energies, but the increase in accuracy due to correction for BSSE is significant. ${ }^{12}$ The counterpoise correction method can be used with DFT functionals, but the improvement in accuracy is minimal in many cases and often not worth the additional computational expense (check to see what is recommended for the particular functional). This is because many modern DFT functionals were originally trained with large basis sets (which are close to the basis set limit) without counterpoise correction. ${ }^{25}$

\section{S2.5 SAPT}

Another strategy to determine the properties of noncovalent complexes is the perturbative approach in which interaction energies are calculated directly as a perturbation to the Hamiltonian for the individual monomers. ${ }^{27}$ Symmetry adapted perturbation theory (SAPT) gives good results for noncovalent interactions, but at a higher cost than MP2 or DFT methods (CPU time scales with system size according to $\mathrm{O}\left(\mathrm{N}^{5-7}\right)$ where $\mathrm{N}$ is the number of basis functions). ${ }^{13}$ It should be noted that the high-order density-fitted SAPT methods (SAPT2+, SAPT2+(3), etc.) as implemented in Psi4 are only available for closed shell singlet systems. ${ }^{28}$ 


\section{S2.6 Recommended Model Chemistries}

The model chemistries used in this work are summarized below and compared in Figure S3.

- "MP2 Model Chemistry” $\rightarrow$ MP2/aug-cc-pVTZ provides reliable results for noncovalent complexes and is a recommended model chemistry for geometry optimization, binding energy calculations, and vibrational frequency analysis. ${ }^{12}$

- "DFT Model Chemistry" $\rightarrow \omega \mathrm{B} 97 \mathrm{M}-\mathrm{V} / \mathrm{def} 2-\mathrm{QZVPPD}$ provides improved accuracy for binding energy calculations compared to MP2/aug-cc-pVTZ. ${ }^{25}$

- "SAPT Model Chemistry" $\rightarrow$ SAPT2+(3) $\delta \mathrm{MP} 2 /$ aug-cc-pVTZ provides improved accuracy for binding energy calculations compared to MP2/aug-cc-pVTZ with the additional benefit of providing an energy decomposition. ${ }^{13}$

- $\quad \operatorname{CCSD}(\mathrm{T}) / \mathrm{CBS}$ provides extremely high accuracy values that are used to benchmark approximate computational methods. It is often referred to as the 'gold standard' of computational chemistry. The large computation demands make CCSD(T)/CBS impractical for routine calculations.

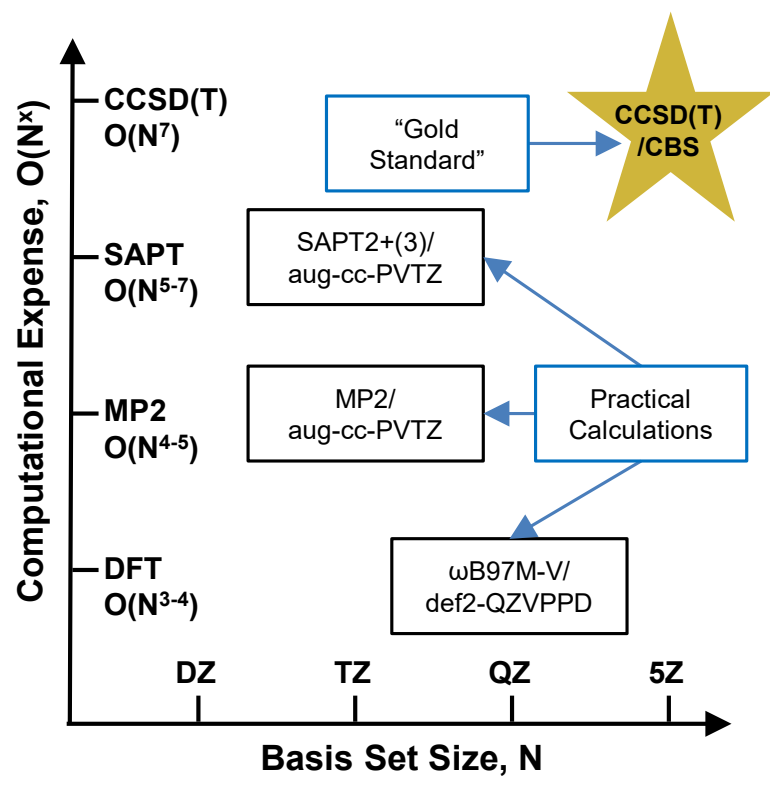

Figure S3. Comparison of model chemistries. 


\section{S2.7 Accuracy}

Performance of the model chemistries used in this work (MP2, DFT, SAPT) can be established by comparing calculation results to benchmark values $(\mathrm{CCSD}(\mathrm{T}) / \mathrm{CBS})$ for sample systems. Binding energies are in good agreement with benchmark values as shown in Table S12.

Table S12. Performance of MP2, DFT and SAPT model chemistries for benchmark systems.

\begin{tabular}{|c|c|c|c|c|c|c|c|c|}
\hline \multirow{2}{*}{ Dimer } & \multicolumn{4}{|c|}{ Binding Energy (kJ/mol) } & \multicolumn{3}{|c|}{ Absolute \% Error } & \multirow{2}{*}{ Source } \\
\hline & $\mathrm{CCSD}(\mathrm{T}) / \mathrm{CBS}$ & MP2 & SAPT & DFT & MP2 & SAPT & DFT & \\
\hline Water & -20.58 & -19.76 & -20.53 & -20.68 & $4.0 \%$ & $0.2 \%$ & $0.5 \%$ & 18 \\
\hline Methanol & -24.09 & -23.31 & -23.92 & -23.77 & $3.2 \%$ & $0.7 \%$ & $1.3 \%$ & 18 \\
\hline Ammonia & -13.13 & -12.63 & -12.58 & -12.75 & $3.8 \%$ & $4.1 \%$ & $2.8 \%$ & 20 \\
\hline Methylamine & -17.41 & -17.12 & -16.96 & -16.85 & $1.6 \%$ & $2.6 \%$ & $3.2 \%$ & 18 \\
\hline Hydrogen Sulfide & -6.99 & -7.28 & -6.66 & -6.40 & $4.3 \%$ & $4.7 \%$ & $8.4 \%$ & 22 \\
\hline \multirow[t]{2}{*}{ Methanethiol } & -13.18 & -13.85 & -12.63 & -12.54 & $5.1 \%$ & $4.2 \%$ & $4.9 \%$ & 22 \\
\hline & & Average & & & $3.7 \%$ & $2.7 \%$ & $3.5 \%$ & \\
\hline
\end{tabular}




\section{S2.8 Complex Geometries}

Optimized geometries for each complex considered in this study are shown in Figure S4 with detailed coordinates provided in a separate Supporting Information file. These geometries were obtained with the MP2/aug-cc-pVTZ model chemistry and are stable minima (no imaginary vibrational frequencies).

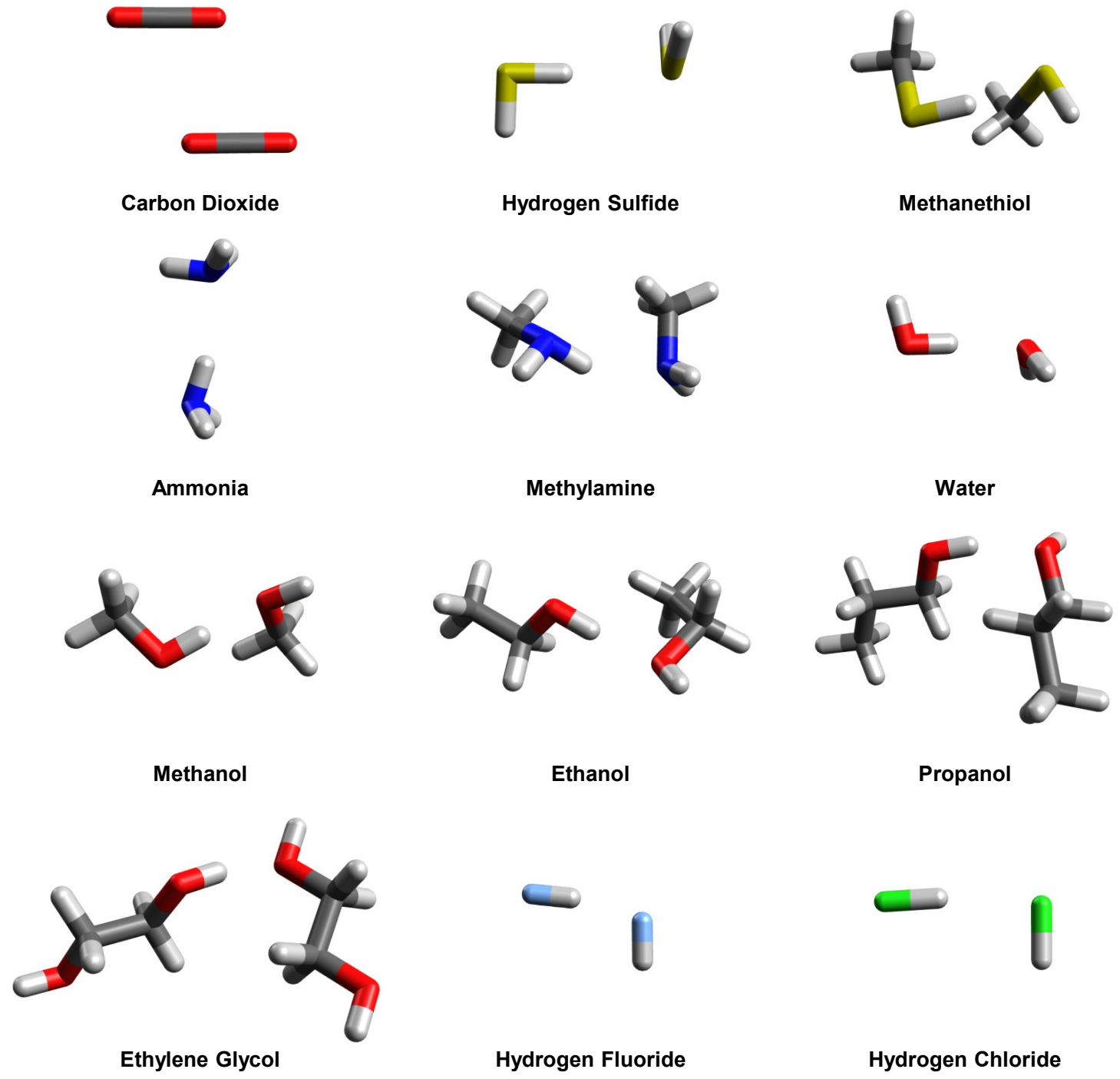

Figure S4. Optimized geometries for complexes studied in this work. 


\section{S3. Statistical Mechanics}

Vibrational frequencies, principle moments of inertia, and binding energies are required to evaluate property changes of complex formation using the RRHO model. These quantities can be obtained using the computational quantum chemistry workflow shown in Figure 5 of the main paper. The first step is to select a model chemistry that will be used for geometry optimization and vibrational frequency calculations. In this study, MP2/aug-cc-pVTZ is applied for these purposes. MP2/aug-cc-pVDZ is a 'less expensive' model chemistry which can be used to initially converge larger structures before the 'more expensive' MP2/aug-cc-pVTZ model chemistry is used for final refinement. Algorithms are available in all electronic structure programs that search for optimum geometries of a noncovalent complex by adjusting atomic coordinates to minimize the total energy of the structure. After geometry optimization is complete, harmonic vibrational frequencies are calculated to check that the geometry optimization converged to a stable structure. If there are any negative or imaginary vibrational frequencies, then the geometry optimization is restarted with tighter termination criteria. This process is repeated until a stable geometry is obtained which is then used to evaluate principle moments of inertia.

Computational chemistry methods calculate harmonic vibrational frequencies $(\omega)$ by sampling points from the potential energy surface of a molecular system and assuming ideal harmonic oscillator behavior. This assumption has proven to be useful for describing vibrational motions for covalently bound molecules. Calculated harmonic frequencies are usually larger than experimentally observed fundamental frequencies $(v)$ due to deviations from harmonic oscillator behavior and approximations in the quantum chemical calculation method. The overestimation of calculated harmonic frequencies is somewhat uniform and frequency scaling factors, $\lambda$, are 
commonly applied to improve agreement with fundamental vibrational frequencies. Scaled harmonic frequencies are then used to evaluate terms in the RRHO model.

Scaling factors are determined by comparing the calculated harmonic frequencies to databases of experimental fundamental frequencies for covalently bonded molecules. Scaling factors determined from this approach are available for most workhorse model chemistries. ${ }^{29-31}$ The recommended scaling factor for MP2/aug-cc-pVTZ is 0.959 which is applied to all harmonic frequencies in this study. Harmonic vibrational frequencies can be obtained at a lower level of theory (such as MP2/aug-cc-pVDZ scaled by 0.9615 ) with minimal loss of accuracy which can save an enormous amount of time for finite difference calculations on larger complexes.

Binding energy, $\Delta E$, is the energy released when forming a noncovalent complex from noninteracting monomers (i.e. monomers which were initially infinitely separated). The binding energy can be evaluated using either the supermolecular or perturbative approaches described previously in the Quantum Chemistry section. Because the binding energy is such an important quantity in the description of noncovalent interactions, it is often calculated at a higher level of theory than what was used for geometry optimization and vibrational frequency calculations. Model chemistries used to evaluate binding energy in this study are MP2/aug-cc-pVTZ, $\omega B 97 M-$ V/Def2-QZVPPD, and SAPT2+(3)SMP2/aug-cc-pVTZ. Results are shown in Table S13 and reasonable agreement is seen between the three different model chemistries. 
Table S13. Noncovalent binding energies $(\mathrm{kJ} / \mathrm{mol})$.

\begin{tabular}{cccc}
\hline Dimer & $\Delta \mathrm{E}_{\mathrm{MP} 2}$ & $\Delta \mathrm{E}_{\mathrm{DFT}}$ & $\Delta \mathrm{E}_{\mathrm{SAPT}}$ \\
\hline Carbon Dioxide & -5.24 & -5.70 & -6.51 \\
Hydrogen Sulfide & -6.93 & -5.41 & -5.98 \\
Methanethiol & -12.74 & -10.59 & -10.80 \\
Ammonia & -12.39 & -12.71 & -12.45 \\
Methylamine & -16.72 & -16.41 & -16.49 \\
Water & -19.78 & -20.77 & -20.55 \\
Methanol & -23.14 & -23.58 & -23.63 \\
Ethanol & -25.40 & -26.22 & -26.10 \\
Propanol & -24.97 & -26.06 & -25.66 \\
Ethylene Glycol & -25.53 & -26.63 & -26.70 \\
Hydrogen Fluoride & -17.72 & -19.41 & -18.97 \\
Hydrogen Chloride & -8.10 & -7.20 & -7.31 \\
\hline
\end{tabular}

Statistical thermodynamics relates molecular energy levels to macroscopic thermodynamic properties via the molecular partition function. Temperature dependent expressions for macroscopic thermodynamic properties (such as enthalpy, H, and entropy, S) are obtained by taking derivatives of the molecular partition function. The rigid rotor-harmonic oscillator (RRHO) model is the most commonly applied set of approximations used to simplify the full molecular partition function for practical calculations. The RRHO model (without hindered rotational terms) is applied in this work to evaluate property changes caused by formation of a noncovalent complex. Karl Irikura's summary of statistical thermodynamics provides an excellent overview of the RRHO model for readers interested in additional information. ${ }^{32} \mathrm{~A}$ thermodynamic pathway for calculating dimerization properties using the RRHO model is shown 
in Figure 2 of the main paper. Estimates for the enthalpy change $(\Delta \mathrm{H})$ and entropy change $(\Delta \mathrm{S})$ due to the formation of a noncovalent dimer are shown in Table S14.

An important result is that $\Delta \mathrm{H}$ is strongly correlated with $\Delta \mathrm{E}$ (see Figure $\mathrm{S} 5$ ). This is because $\Delta \mathrm{H}$ is dominated by $\Delta \mathrm{E}$ and secondary terms that dependent on vibrational frequencies (such as $\Delta \mathrm{ZPE}$ and $\left.\Delta \mathrm{H}_{\mathrm{vib}}\right)$ also correlate with $\Delta \mathrm{E}$. The correlation between these terms is consistent with studies which have shown the intermolecular stretching force constant is directly proportional to bond dissociation energy. ${ }^{33,34}$

Table S14. Enthalpy change $(\mathrm{kJ} / \mathrm{mol})$ and entropy change $(\mathrm{J} /(\mathrm{mol} . \mathrm{K}))$ of dimer formation.

\begin{tabular}{cccccc}
\hline Dimer & Formula & $\Delta \mathrm{H}_{\mathrm{SAPT}}{ }^{\mathrm{a}}$ & $\Delta \mathrm{H}_{\mathrm{MP} 2}{ }^{\mathrm{b}}$ & $\Delta \mathrm{H}_{\mathrm{DFT}}{ }^{\mathrm{c}}$ & $\Delta \mathrm{S}$ \\
\hline Carbon dioxide & $\left(\mathrm{CO}_{2}\right)_{2}$ & -3.99 & -2.72 & -3.17 & -58.79 \\
Hydrogen Sulfide & $\left(\mathrm{H}_{2} \mathrm{~S}\right)_{2}$ & -0.56 & -1.51 & 0.00 & -66.81 \\
Methanethiol & $\left(\mathrm{CH}_{3} \mathrm{SH}\right)_{2}$ & -5.71 & -7.64 & -5.50 & -116.61 \\
Ammonia & $\left(\mathrm{NH}_{3}\right)_{2}$ & -6.39 & -6.33 & -6.65 & -65.69 \\
Methylamine & $\left(\mathrm{CH}_{3} \mathrm{NH}_{2}\right)_{2}$ & -10.61 & -10.84 & -10.52 & -111.58 \\
Water & $\left(\mathrm{H}_{2} \mathrm{O}\right)_{2}$ & -13.70 & -12.94 & -13.92 & -83.90 \\
Methanol & $\left(\mathrm{CH}_{3} \mathrm{OH}\right)_{2}$ & -17.06 & -16.57 & -17.01 & -96.27 \\
Ethanol & $\left(\mathrm{C}_{2} \mathrm{H}_{5} \mathrm{OH}\right)_{2}$ & -19.61 & -18.90 & -19.72 & -111.12 \\
Propanol & $\left(\mathrm{C}_{3} \mathrm{H}_{7} \mathrm{OH}\right)_{2}$ & -19.27 & -18.57 & -19.67 & -132.49 \\
Ethylene Glycol & $\left(\mathrm{C}_{2} \mathrm{H}_{6} \mathrm{O}_{2}\right)_{2}$ & -20.09 & -18.92 & -20.02 & -108.37 \\
Hydrogen Fluoride & $\left(\mathrm{HF}_{2}\right.$ & -14.89 & -13.63 & -15.33 & -84.64 \\
Hydrogen Chloride & $\left(\mathrm{HCl}_{2}\right.$ & -4.36 & -5.15 & -4.25 & -74.78 \\
\hline
\end{tabular}

RRHO $\Delta \mathrm{H}$ evaluated using harmonic frequencies calculated with MP2/aug-cc-pVTZ combined with (a) $\Delta \mathrm{E}_{\mathrm{MP} 2}$, (b) $\Delta \mathrm{E}_{\mathrm{DFT}}$, or (c) $\Delta \mathrm{H}$ can be calculated using $\Delta \mathrm{E}_{\mathrm{SAPT}}$. All calculations carried out at $298.15 \mathrm{~K}$ and $101,325 \mathrm{~Pa}$. 


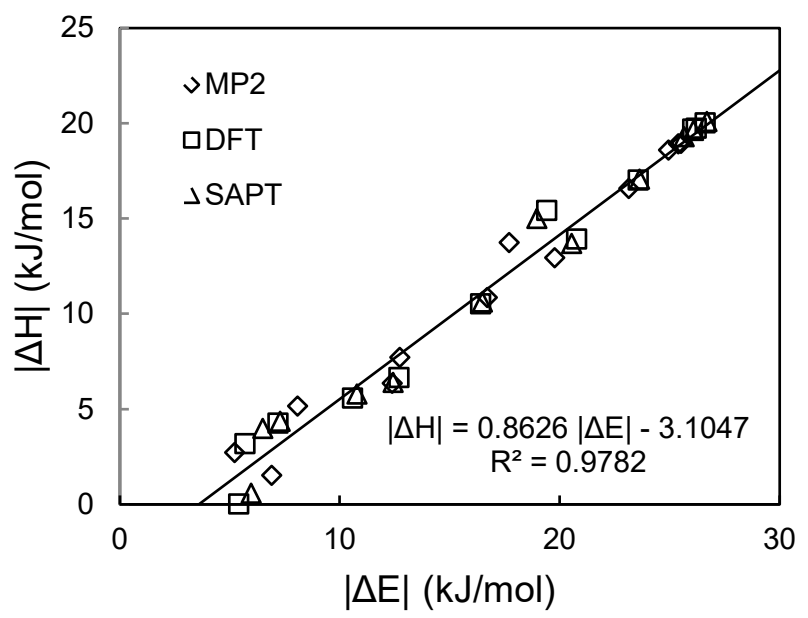

Figure S5. Correlation between $\Delta \mathrm{H}$ and $\Delta \mathrm{E}$ for various methods used with the aug-cc-pVTZ basis sets. 


\section{S4. Simplified TPT-1/CT Relationships}

Tables S15 and S16 summarize the data presented in Figures 3 and 4 of the main paper.

Table S15. Reduced association enthalpy estimated from several approaches.

\begin{tabular}{ccccc}
\hline & & & $-\Delta \mathrm{H} / \mathrm{R}(\mathrm{K})$ & \\
\cline { 3 - 4 } Compound & Scheme & ${\mathrm{QC} / \mathrm{SM}^{\mathrm{a}}}^{\mathrm{a}}$ & PC-SAFT $^{\mathrm{b}}$ & $\mathrm{CPA}^{\mathrm{b}}$ \\
\hline Carbon Dioxide & & 479 & 176 & 403 \\
Hydrogen Sulfide & 4C & 68 & 65 & 373 \\
Methanethiol & 2B & 686 & 655 & 865 \\
Ammonia & 4B & 769 & 624 & 635 \\
Methylamine & 2B & 1276 & 653 & 1376 \\
Water & 4C & 1648 & 1703 & 1573 \\
Methanol & 2B & 2052 & 2304 & 2315 \\
Ethanol & 2B & 2358 & 2574 & 2590 \\
Propanol & 2B & 2318 & 2464 & 2526 \\
Ethylene Glycol & 4C & 2416 & 2006 & 2376 \\
Hydrogen Fluoride & 2B & 1791 & 1676 & 1385 \\
Hydrogen Chloride & 2B & 524 & 385 & 499 \\
\hline
\end{tabular}

(a) Quantum Chemistry + Statistical Mechanics: SAPT2+(3) $\delta M P 2 /$ aug-cc-pVTZ binding energy, MP2/aug-cc-pVTZ harmonic vibrational frequencies, RRHO approximation without hindered rotation. ${ }^{(b)}$ Estimated using Eq. (14). 
Table S16. Reduced association entropy estimated from several approaches.

\begin{tabular}{ccccc}
\hline \multirow{2}{*}{ compound } & Scheme & \multicolumn{3}{c}{$\Delta \mathrm{S} / \mathrm{R}$} \\
\cline { 3 - 5 } & & QC/SM & PC-SAFT $^{\mathrm{b}}$ & CPA $^{\mathrm{b}}$ \\
\hline Carbon Dioxide & 4C & -7.1 & -9.8 & -8.9 \\
Hydrogen Sulfide & 4C & -8.0 & -5.8 & -8.4 \\
Methanethiol & 2B & -14.0 & -11.6 & -9.8 \\
Ammonia & 4B & -7.9 & -7.4 & -7.1 \\
Methylamine & 2B & -13.4 & -9.8 & -9.9 \\
Water & 4C & -10.1 & -8.5 & -8.0 \\
Methanol & 2B & -11.6 & -9.4 & -9.5 \\
Ethanol & 2B & -13.4 & -10.4 & -11.0 \\
Propanol & 2B & -15.9 & -11.1 & -10.8 \\
Ethylene Glycol & 4C & -13.0 & -8.7 & -9.0 \\
Hydrogen Fluoride & 2B & -10.2 & -6.8 & -6.1 \\
Hydrogen Chloride & 2B & -9.0 & -6.9 & -7.4 \\
\hline
\end{tabular}

(a) Quantum Chemistry + Statistical Mechanics: SAPT2+(3)反MP2/aug-cc-pVTZ binding energy, MP2/aug-cc-pVTZ harmonic vibrational frequencies, RRHO approximation without hindered rotation. ${ }^{\left({ }^{b}\right)}$ Estimated using Eq. (16). 


\section{S5. Virial Coefficients and Phase Diagrams}

$\mathrm{P}-\mathrm{T}$ and $\rho$-T diagrams for the saturation line as well as a $\rho-\mathrm{P}$ diagram covering the saturated and supercritical regions for selected compounds (water, ammonia, and hydrogen chloride) are shown in Figures S6 and S7. Saturation curves are only displayed up to $T_{r}=1.0$ due to the known limitation that association models over-predict the critical point. The $\mathrm{T}_{\mathrm{r}}=1.02$ isotherm shows a phase split in the critical region (further illustrating this limitation). The $\mathrm{T}_{\mathrm{r}}=1.05,1.10$, and 1.20 isotherms predicted using 'CPA 4P' parameter sets show satisfactory agreement with reference data over a wide pressure range. Similar results were obtained for the 'CPA 5P', 'PCSAFT 4P' and 'PC-SAFT 5P' parameter sets.
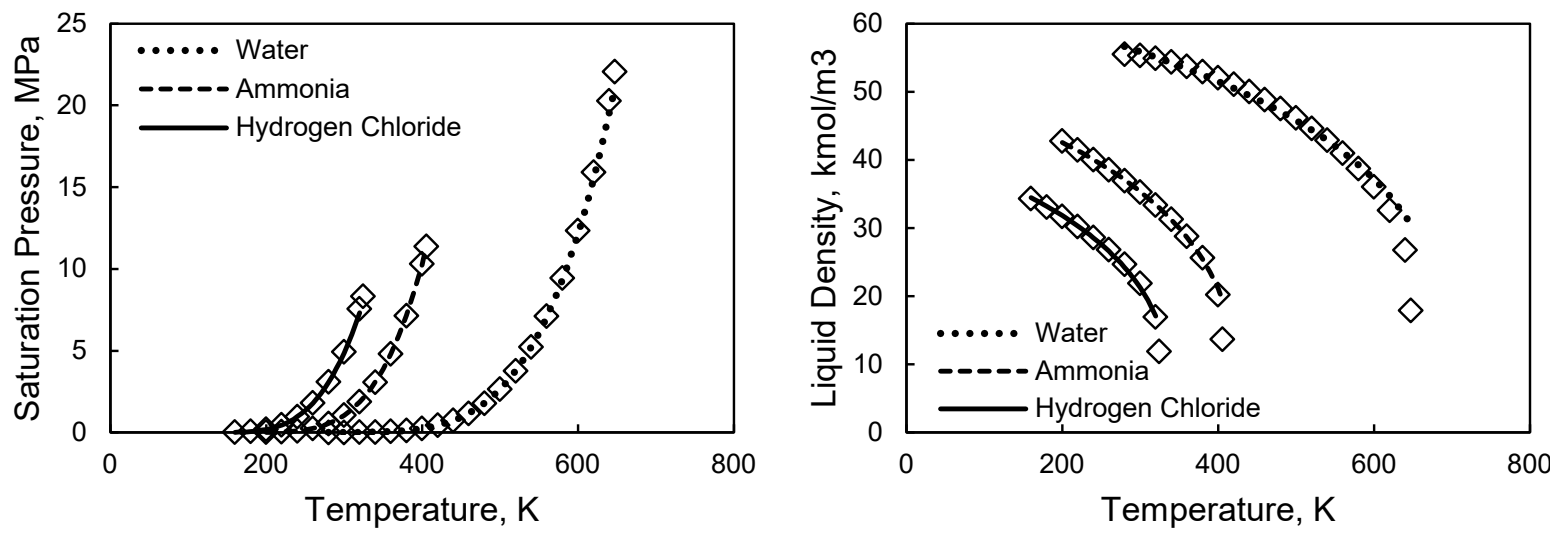

Figure S6. Vapor pressure and saturated liquid density predictions for selected compounds. ${ }^{10}$

Second virial coefficients are a direct measure of how well a thermodynamic model represents intermolecular forces and complexation for associating compounds. The '4P' parameter sets proposed in this work show improved agreement with experimental second virial coefficient data relative to the ' $5 \mathrm{P}$ ' base case (where all five parameters are adjusted to match experimental data). This improvement is an indication that the association energies estimated with the proposed workflow are more physically reasonable compared to completely empirical parameter sets. 

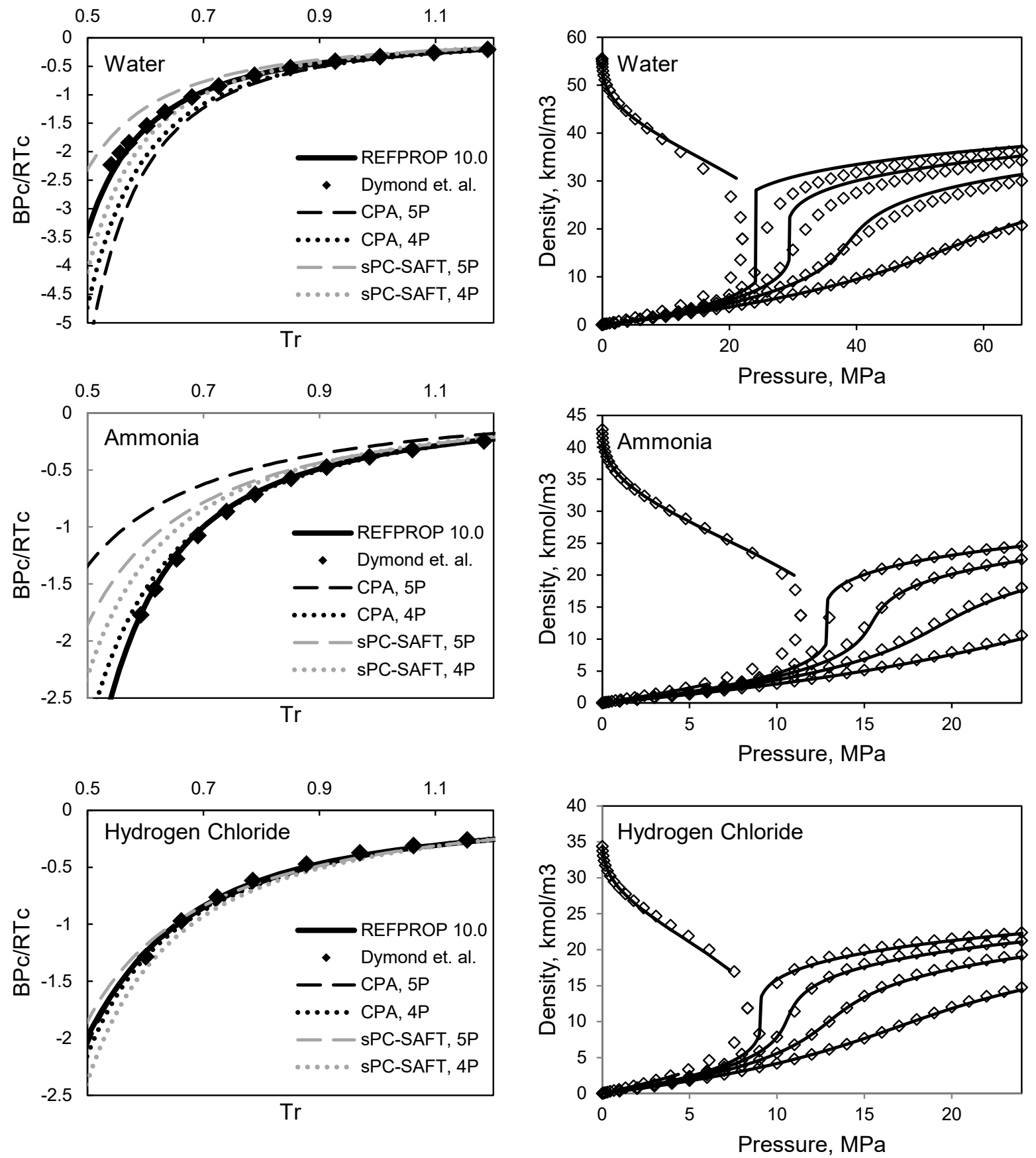

Figure S7. Second virial coefficient and high pressure density predictions for selected compounds. The high pressure density plots shown in the right column were generated using 'CPA 4P' parameters for the $\mathrm{T}_{\mathrm{r}}=1.02,1.05,1.10$, and 1.20 isotherms. ${ }^{35,36}$ 


\section{REFERENCES}

(1) Gross, J.; Sadowski, G. Application of the Perturbed-Chain SAFT Equation of State to Associating Systems. Ind. Eng. Chem. Res. 2002, 41, 5510-5515.

(2) Liang, X.; Tsivintzelis, I.; Kontogeorgis, G. M. Modeling Water Containing Systems with the Simplified PC-SAFT and CPA Equations of State. Ind. Eng. Chem. Res. 2014, 53, 1449314507.

(3) Tybjerg, P. C. V.; Kontogeorgis, G. M.; Michelsen, M. L.; Stenby, E. H. Phase equilibria modeling of methanol-containing systems with the CPA and sPC-SAFT equations of state. Fluid Phase Equilib. 2010, 288, 128-138.

(4) Liang, X.; Thomsen, K.; Yan, W.; Kontogeorgis, G. M. Prediction of the vapor-liquid equilibria and speed of sound in binary systems of 1-alkanols and n-alkanes with the simplified PC-SAFT equation of state. Fluid Phase Equilib. 2013, 360, 222-232.

(5) Liang, X.; Yan, W.; Thomsen, K.; Kontogeorgis, G. M. Modeling the liquid-liquid equilibrium of petroleum fluid and polar compounds containing systems with the PC-SAFT equation of state. Fluid Phase Equilib. 2015, 406, 147-155.

(6) Diamantonis, N. I.; Economou, I. G. Modeling the phase equilibria of a H2O-CO2 mixture with PC-SAFT and tPC-PSAFT equations of state. Molecular Physics 2012, 110, 1205-1212.

(7) Tsivintzelis, I.; Kontogeorgis, G. M.; Michelsen, M. L.; Stenby, E. H. Modeling phase equilibria for acid gas mixtures using the CPA equation of state. Part II: Binary mixtures with CO2. Fluid Phase Equilib. 2011, 306, 38-56. 
(8) Tsivintzelis, I.; Kontogeorgis, G. M.; Michelsen, M. L.; Stenby, E. H. Modeling phase equilibria for acid gas mixtures using the CPA equation of state. I. Mixtures with H2S. AIChE J. 2010, 56, 2965-2982.

(9) Kaarsholm, M.; Derawi, S. O.; Michelsen, M. L.; Kontogeorgis, G. M. Extension of the Cubic-plus-Association (CPA) Equation of State to Amines. Ind. Eng. Chem. Res. 2005, 44, 4406-4413.

(10) Rowley, R.L.; Wilding, W. V.; Oscarson, J. L.; Knotts, T. A.; Giles, N. F. DIPPR® Data Compilation of Pure Chemical Properties. Design Institute for Physical Properties, AIChE, New York, NY (2016).

(11) Mardirossian, N.; Head-Gordon, M. Thirty years of density functional theory in computational chemistry: an overview and extensive assessment of 200 density functionals. Molecular Physics 2017, 115, 2315-2372.

(12) Riley, K. E.; Platts, J. A.; Řezáč, J.; Hobza, P.; Hill, J. G. Assessment of the Performance of MP2 and MP2 Variants for the Treatment of Noncovalent Interactions. J. Phys. Chem. A 2012, 116, 4159-4169.

(13) Parker, T. M.; Burns, L. A.; Parrish, R. M.; Ryno, A. G.; Sherrill, C. D. Levels of symmetry adapted perturbation theory (SAPT). I. Efficiency and performance for interaction energies. J. Chem. Phys. 2014, 140, 094106.

(14) Frisch, M. J.; Trucks, G. W.; Schlegel, H. B.; Scuseria, G. E.; Robb, M. A.; Cheeseman, J. R.; Scalmani, G.; Barone, V.; Petersson, G. A.; Nakatsuji, H.; Li, X.; Caricato, M.; Marenich, A. V.; Bloino, J.; Janesko, B. G.; Gomperts, R.; Mennucci, B.; Hratchian, H. P.; Ortiz, J. V.; 
Izmaylov, A. F.; Sonnenberg, J. L.; Williams-Young, D.; Ding, F.; Lipparini, F.; Egidi, F.; Goings, J.; Peng, B.; Petrone, A.; Henderson, T.; Ranasinghe, D.; Zakrzewski, V. G.; Gao, J.; Rega, N.; Zheng, G.; Liang, W.; Hada, M.; Ehara, M.; Toyota, K.; Fukuda, R.; Hasegawa, J.; Ishida, M.; Nakajima, T.; Honda, Y.; Kitao, O.; Nakai, H.; Vreven, T.; Throssell, K.; Montgomery, J. A., Jr.; Peralta, J. E.; Ogliaro, F.; Bearpark, M. J.; Heyd, J. J.; Brothers, E. N.; Kudin, K. N.; Staroverov, V. N.; Keith, T. A.; Kobayashi, R.; Normand, J.; Raghavachari, K.; Rendell, A. P.; Burant, J. C.; Iyengar, S. S.; Tomasi, J.; Cossi, M.; Millam, J. M.; Klene, M.; Adamo, C.; Cammi, R.; Ochterski, J. W.; Martin, R. L.; Morokuma, K.; Farkas, O.; Foresman, J. B.; Fox, D. J. Gaussian 16, Gaussian, Inc.: Wallingford CT, 2016.

(15) Barca, G. M.; Bertoni, C.; Carrington, L; Datta, D.; De Silva, N; Deustua, J. E.; Fedorov, D. G.; Gour, J. R.; Gunina, A. O.; Guidez, E.; Harville, T.; Irle, S.; Ivanic, J.; Kowalski, K.; Leang, S. S.; Li, H.; Li, W.; Lutz, J. J.; Magoulas, I.; Mato, J.; Mironov, V.; Nakata, H.; Pham, B. Q.; Piecuch, P.; Poole, D.; Pruitt, S. R.; Rendell, A. P.; Roskop, L. B.; Ruedenberg, K.; Sattasathuchana, T.; Schmidt, M. W.; Shen, J.; Slipchenko, L.; Sosonkina, M.; Sundriyal, V.; Tiwari, A.; Galvez Vallejo, J. L.; Westheimer, B.; Włoch, M.; Xu, P.; Zahariev, F.; Gordon, M. S. Recent developments in the general atomic and molecular electronic structure system. $J$. Chem. Phys. 2020, 152, 154102.

(16) Shao, Y.; Gan, Z.; Epifanovsky, E.; Gilbert, A. T. B.; Wormit, M.; Kussmann, J.; Lange, A. W.; Behn, A.; Deng, J.; Feng, X.; Ghosh, D.; Goldey, M.; Horn, P. R.; Jacobson, L. D.; Kaliman, I.; Khaliullin, R. Z.; Kús, T.; Landau, A.; Liu, J.; Proynov, E. I.; Rhee, Y. M.; Richard, R. M.; Rohrdanz, M. A.; Steele, R. P.; Sundstrom, E. J.; Woodcock III, H. L.; Zimmerman, P. M.; Zuev, D.; Albrecht, B.; Alguire, E.; Austin, B.; Beran, G. J. O.; Bernard, Y. A.; Berquist, E.; Brandhorst, K.; Bravaya, K. B.; Brown, S. T.; Casanova, D.; Chang, C.-M.; Chen, Y.; Chien, S. 
H.; Closser, K. D.; Crittenden, D. L.; Diedenhofen, M.; DiStasio Jr., R. A.; Dop, H.; Dutoi, A. D.; Edgar, R. G.; Fatehi, S.; Fusti-Molnar, L.; Ghysels, A.; Golubeva-Zadorozhnaya, A.; Gomes, J.; Hanson-Heine, M. W. D.; Harbach, P. H. P.; Hauser, A. W.; Hohenstein, E. G.; Holden, Z. C.; Jagau, T.-C.; Ji, H.; Kaduk, B.; Khistyaev, K.; Kim, J.; Kim, J.; King, R. A.; Klunzinger, P.; Kosenkov, D.; Kowalczyk, T.; Krauter, C. M.; Lao, K. U.; Laurent, A.; Lawler, K. V.; Levchenko, S. V.; Lin, C. Y.; Liu, F.; Livshits, E.; Lochan, R. C.; Luenser, A.; Manohar, P.; Manzer, S. F.; Mao, S.-P.; Mardirossian, N.; Marenich, A. V.; Maurer, S. A.; Mayhall, N. J.; Oana, C. M.; Olivares-Amaya, R.; O’Neill, D. P.; Parkhill, J. A.; Perrine, T. M.; Peverati, R.; Pieniazek, P. A.; Prociuk, A.; Rehn, D. R.; Rosta, E.; Russ, N. J.; Sergueev, N.; Sharada, S. M.; Sharmaa, S.; Small, D. W.; Sodt, A.; Stein, T.; Stück, D.; Su, Y.-C.; Thom, A. J. W.; Tsuchimochi, T.; Vogt, L.; Vydrov, O.; Wang, T.; Watson, M. A.; Wenzel, J.; White, A.; Williams, C. F.; Vanovschi, V.; Yeganeh, S.; Yost, S. R.; You, Z.-Q.; Zhang, I. Y.; Zhang, X.; Zhou, Y.; Brooks, B. R.; Chan, G. K. L.; Chipman, D. M.; Cramer, C. J.; Goddard III, W. A.; Gordon, M. S.; Hehre, W. J.; Klamt, A.; Schaefer III, H. F.; Schmidt, M. W.; Sherrill, C. D.; Truhlar, D. G.; Warshel, A.; Xua, X.; Aspuru-Guzik, A.; Baer, R.; Bell, A. T.; Besley, N. A.; Chai, J.-D.; Dreuw, A.; Dunietz, B. D.; Furlani, T. R.; Gwaltney, S. R.; Hsu, C.-P.; Jung, Y.; Kong, J.; Lambrecht, D. S.; Liang, W.; Ochsenfeld, C.; Rassolov, V. A.; Slipchenko, L. V.; Subotnik, J. E.; Van Voorhis, T.; Herbert, J. M.; Krylov, A. I.; Gill, P. M. W.; Head-Gordon, M. Advances in molecular quantum chemistry contained in the Q-Chem 4 program package. Mol. Phys. 2015, 113, 184-215.

(17) Parrish, R. M.; Burns, L. A.; Smith, D. G. A.; Simmonett, A. C; DePrince, A. E., III; Hohenstein, E. G.; Bozkaya, U.; Sokolov, A. Y.; Di Remigio, R.; Richard, R. M.; Gonthier, J. F.; James, A. M.; McAlexander, H. R.; Kumar, A.; Saitow, M.; Wang, X.; Pritchard, B. P.; Verma, 
P.; Schaefer, H. F., III; Patkowski, K.; King, R. A.; Valeev, E. F.; Evangelista, F. A.; Turney, J. M.; Crawford, T. D.; Sherrill, C. D. Psi4 1.1: An Open-Source Electronic Structure Program Emphasizing Automation, Advanced Libraries, and Interoperability. J. Chem. Theory Comput. 2017, 13, 3185-3197.

(18) Řezáč, J.; Riley, K. E.; Hobza, P. S66: A Well-balanced Database of Benchmark Interaction Energies Relevant to Biomolecular Structures. J. Chem. Theory Comput. 2011, 7, 2427-2438.

(19) Granatier, J.; Pitoňák, M.; Hobza, P. Accuracy of Several Wave Function and Density Functional Theory Methods for Description of Noncovalent Interaction of Saturated and Unsaturated Hydrocarbon Dimers. J. Chem. Theory Comput. 2012, 8, 2282-2292.

(20) Řezáč, J.; Hobza, P. Describing Noncovalent Interactions beyond the Common Approximations: How Accurate Is the "Gold Standard," $\operatorname{CCSD}(\mathrm{T})$ at the Complete Basis Set Limit?. J. Chem. Theory Comput. 2013, 9, 2151-2155.

(21) Řezáč, J.; Riley, K. E.; Hobza, P. Benchmark Calculations of Noncovalent Interactions of Halogenated Molecules. J. Chem. Theory Comput. 2012, 8, 4285-4292.

(22) Mintz, B. J.; Parks, J. M. Benchmark Interaction Energies for Biologically Relevant Noncovalent Complexes Containing Divalent Sulfur. J. Phys. Chem. A 2012, 116, 1086-1092.

(23) Lao, K. U.; Schäffer, R.; Jansen, G.; Herbert, J. Accurate Description of Intermolecular Interactions Involving Ions Using Symmetry-Adapted Perturbation Theory. J. Chem. Theory Comput. 2015, 11, 2473-2486. 
(24) Jensen, F. Atomic orbital basis sets. Wiley Interdiscip. Rev.: Comput. Mol. Sci. 2012, 3, 273-295.

(25) Mardirossian, N.; Head-Gordon, M. $\omega B 97 \mathrm{M}-\mathrm{V}$ : A combinatorially optimized, rangeseparated hybrid, meta-GGA density functional with VV10 nonlocal correlation. J. Chem. Phys. 2016, 144, 214110 .

(26) Boys, S. F.; Bernardi, F. The calculation of small molecular interactions by the differences of separate total energies. Some procedures with reduced errors. Molecular Physics 1970, 19, 553-566.

(27) Jeziorski, B.; Moszynski, R.; Szalewicz, K. Perturbation Theory Approach to Intermolecular Potential Energy Surfaces of van der Waals Complexes. Chem. Rev. 1994, 94, 1887-1930.

(28) Hohenstein, E. G.; Sherrill, C. D. Density fitting of intramonomer correlation effects in symmetry-adapted perturbation theory. J. Chem. Phys. 2010, 133, 014101.

(29) Merrick, J. P.; Moran, D.; Random, L. An evaluation of harmonic vibrational frequency scale factors. J. Phys. Chem. A 2007, 111, 11683-11700.

(30) Scott, A. P.; Random, L. Harmonic Vibrational Frequencies: An Evaluation of Hartree-Fock, Møller-Plesset, Quadratic Configuration Interaction, Density Functional Theory, and Semiempirical Scale Factors. J. Phys. Chem. 1996, 100, 16502-16513.

(31) Irikura, K. K.; Johnson, R. D; Kacker, R. N. Uncertainties in Scaling Factors for ab Initio Vibrational Frequencies. J. Phys. Chem. A 2005, 109, 8430-8437. 
(32) Irikura, K. K. Essential Statistical Thermodynamics. Computational Thermochemistry [Online]; Irikura, K. K., Frurip, D. J, Eds.; ACS Symposium Series; American Chemical Society: Washington, DC, 1998; pp 441-454. https://pubs.acs.org/doi/10.1021/bk-19980677.ch022 (accessed October 12, 2020)

(33) Alkorta, I.; Legon, A. C. Strengths of non-covalent interactions in hydrogen-bonded complexes $\mathrm{B} \cdots \mathrm{HX}$ and halogen-bonded complexes $\mathrm{B} \cdots \mathrm{XY}(\mathrm{X}, \mathrm{Y}=\mathrm{F}, \mathrm{Cl})$ : an ab initio investigation. New J. Chem. 2018, 42, 10548-10554.

(34) Legon, A. C. A reduced radial potential energy function for the halogen bond and the hydrogen bond in complexes $\mathrm{B} \cdots \mathrm{XY}$ and $\mathrm{B} \cdots \mathrm{HX}$, where $\mathrm{X}$ and $\mathrm{Y}$ are halogen atoms. Phys. Chem. Chem. Phys. 2014, 16, 12415-12421.

(35) Dymond, J. H.; Marsh, K. N.; Wilhoit, R. C.; Wong, K. C. Virial Coefficients of Pure Gases and Mixtures, ${ }^{\text {st }}$ Edition; Frenkel, M., Marsh, K. N.; Physical Chemistry Series; Springer: Berlin, 2003.

(36) Lemmon, E.W.; Bell, I.H.; Huber, M.L.; McLinden, M.O. NIST Standard Reference Database 23: Reference Fluid Thermodynamic and Transport Properties-REFPROP, Version 10.0; National Institute of Standards and Technology, Standard Reference Data Program: Gaithersburg, 2018. 